\title{
2-(N-Methylanilino)-2-phenylthioacetonitrile: a Useful Reagent for Preparation of Conjugated $\alpha$-Amino Alkenenitriles via Tandem Alkylation and Dehydrosulphenylation
}

\author{
Jim-Min Fang * and Chih-Cheng Chen \\ Department of Chemistry, National Taiwan University, Taipei, Taiwan 10764, Republic of China
}

\begin{abstract}
Alkylation of the anion of 2-( $N$-methylanilino)-2-phenylthioacetonitrile 1 with halogenoalkanes resulted in concurrent elimination of benzenethiol to give conjugated $\alpha$-aminoalkenenitriles of $2 E$ configuration. Counterattack by bromide and benzenethiolate ions was observed in the prolonged reactions of 1 with 1,4-dibromobut-2-ene and 3-bromo-1-(trimethylsilyl)prop-1-yne.
\end{abstract}

$\alpha$-Aminonitrile alkenes and dienes have been extensively studied for both their special captodative effects ${ }^{1}$ and general use in organic synthesis, where they can function as acceptors in Michael reactions, ${ }^{2}$ substrates in Diels-Alder reactions, ${ }^{3}$ and radicophiles in intramolecular cyclisations. ${ }^{4}$ Previous methods for preparation of $\alpha$-aminoalkenenitriles include (1) condensation of 2-aminoacetonitrile with an aldehyde or an $\alpha, \beta$ unsaturated aldehyde by using the Peterson method or related procedures, ${ }^{5}(2)$ condensation of an $\alpha$-chloroacetaldehyde or an $\alpha, \beta$-unsaturated aldehyde with an amine and $\mathrm{KCN}$ (the Strecker procedure), followed by base-catalysed dehydrochlorination or double bond migration, ${ }^{3,6}$ and (3) treatment of an amide with phosgene followed by substitution with cyanide ion. ${ }^{7}$ Besides being tedious to carry out, these methods are limited to the availability of starting materials, and are hardly applicable to compounds containing other sensitive functional groups. We herein describe an expeditious preparative method for various $\alpha$ amino alkenenitriles by using the title reagent 1 and alkyl halides 2 (Scheme 1).

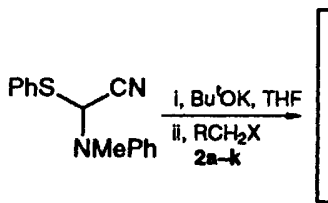

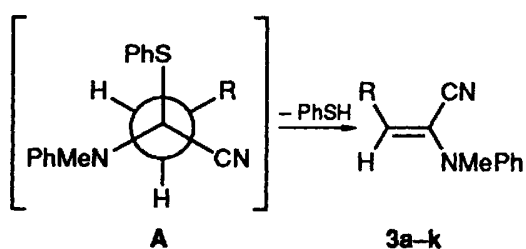

Scheme 1
The title compound, 2-( $N$-methylanilino $)-2-$ phenylthio- 
Table 1. Conjugated $\alpha$-aminoalkenenitriles prepared from 1 and halides

\begin{tabular}{|c|c|c|c|c|c|c|}
\hline Entry & Alkyl halide 2 & $\begin{array}{l}\text { Reaction } \\
\text { temp. }\left({ }^{\circ} \mathrm{C}\right)\end{array}$ & $\begin{array}{l}\text { Reaction } \\
\text { time (h) }\end{array}$ & $\begin{array}{l}\text { Product }^{a} \\
(\% \text { yield })\end{array}$ & $\mathbf{R}$ & $\begin{array}{l}\text { Literature method } \\
\% \text { yield }(E: Z)\end{array}$ \\
\hline 1 & $\mathrm{MeI}$ & $\mathrm{RT}^{*}$ & 1 & $3 a(83)$ & $\mathbf{H}$ & $(1):{ }^{e} 83$ \\
\hline 2 & EtI & RT & 1.5 & $3 \mathbf{b}(82)$ & $\mathrm{Me}$ & \\
\hline 3 & BuI & RT & 12 & $3 c(61)$ & Pr & $(1) ;^{f} 58$ (mixture) \\
\hline 4 & $\mathrm{Br}\left(\mathrm{CH}_{2}\right)_{3} \mathrm{I}$ & 60 & 24 & $3 d(62)$ & $\mathrm{Br}\left(\mathrm{CH}_{2}\right)_{2}$ & \\
\hline 5 & $\mathrm{I}\left(\mathrm{CH}_{2}\right)_{5} \mathrm{I}$ & RT & 20 & $3 e(50)$ & $\mathrm{I}\left(\mathrm{CH}_{2}\right)_{4}$ & \\
\hline 6 & $\mathrm{ICH}_{2} \mathrm{CO}_{2} \mathrm{Et}$ & 60 & 24 & $3 f(72)$ & $\mathrm{CO}_{2} \mathrm{Et}$ & \\
\hline 7 & $\mathrm{PhCH}_{2} \mathrm{Br}$ & RT & 1.5 & $3 g(64)$ & $\mathrm{Ph}$ & $(1) ;^{f} 100$ (mixture) \\
\hline 8 & $\mathrm{CH}_{2}=\mathrm{CHCH}_{2} \mathrm{Br}$ & RT & 20 & $3 \mathrm{~h}(61)$ & $\mathrm{CH}_{2}=\mathrm{CH}$ & $(1) ;{ }^{*} 78(2: 1)$ \\
\hline 9 & $\mathrm{PhCH}=\mathrm{CHCH}_{2} \mathrm{Cl}$ & 60 & 1 & $3 i(63)$ & $\mathrm{PhCH}=\mathrm{CH}$ & $(1) ;^{h} 85(1: 1)$ \\
\hline 10 & $\mathrm{MeCH}=\mathrm{CHCH}_{2} \mathrm{Cl}$ & 60 & 24 & $3 \mathrm{j}(61)^{b}$ & $\mathrm{MeCH}=\mathrm{CH}$ & (1) $)^{h} 84(1: 1)$ \\
\hline 11 & $\mathrm{BrCH}=\mathrm{CHCH}_{2} \mathrm{Br}$ & RT & 12 & $3 \mathbf{k}(72)$ & $\mathrm{BrCH}=\mathrm{CH}$ & \\
\hline 12 & $\mathrm{BrCH}_{2} \mathrm{CH}=\mathrm{CHCH}_{2} \mathrm{Br}$ & RT & 50 & $31(60)$ & $\mathrm{PhSCH}_{2} \mathrm{CH}=\mathrm{CH}$ & \\
\hline 13 & $\mathrm{MeSi}_{3} \mathrm{CCCH}_{2} \mathrm{Br}$ & RT & 72 & $3 \mathrm{~m}(55)^{\mathrm{c}}$ & $\mathrm{PhSCH}=\mathrm{CH}$ & \\
\hline
\end{tabular}

$\mathrm{RT}=$ room temp. ${ }^{a}$ All new products are characterised by spectral methods (IR, MS, ${ }^{1} \mathrm{H}$ and ${ }^{13} \mathrm{C}$ NMR) and combustion analyses. ${ }^{b}$ The prepared $\alpha-$ aminoalkenitriles 3 are exclusively of the $2 E$-form, except for $3 \mathrm{j}$ which consists of $2 E$ - and $2 Z$-isomers $(2: 1){ }^{c}$ The product mixture is composed of the $2 E, 4 E$ - and $2 E, 4 Z$-dienenitriles in a ratio of $3: 2{ }^{d}{ }^{d}$ Refer to the previous method (1) described in the text. ${ }^{e}$ By addition of $\alpha$-aminoacetonitrile with formaldehyde according to the Peterson method, see ref. $2^{f}$ By the Peterson method, see ref. 5 (K. Takahashi et al.). ${ }^{g}$ The allylic alcohol obtained by addition of 2-aminoacetonitrile to acrolein was activated as the acetate and subjected to base-catalysed elimination, see ref. 5 (C. C. Lin). ${ }^{h} \mathrm{By}$ the Peterson method, see ref. 3 (J. M. Fang et al.).

acetonitrile $^{8}$ was prepared in $91 \%$ yield from $2-(N$-methylanilino)acetonitrile by deprotonation with lithium di-isopropylamide and subsequent treatment with diphenyl disulphide in THF solution. Compound 1 is a colourless solid, m.p. 61$61.5^{\circ} \mathrm{C}$ (from hexane). It is stable, and no apparent decomposition occurs after storage for months under a nitrogen atmosphere at room temperature. To prepare $\alpha$-aminoalkenenitriles 3a-f (Table 1), compound 1 was simply treated with equimolar amounts of $\mathrm{Bu}^{\mathrm{t} O K}$ and iodoalkanes in THF solution either at room temperature or with mild heating. These reactions are selective in giving the monosubstitution products 3d and 3e with retention of other halogen atoms (entries 4 and 5 ). If allylic bromides or allylic chlorides were used instead of iodoalkanes, the $\alpha$-amino dienenitriles were then obtained in modest yields (entries 8-12).

The nature of intermediate $A$ was characterised by NMR spectral analyses when iodomethane or allyl bromide was used as the alkylating agent. ${ }^{9}$ The facile elimination of the benzenethiol molecule, occurring either under the alkaline reaction conditions or during the $\mathrm{SiO}_{2}$ chromatographic workup, is presumably promoted by the electron-donating $\alpha$-amino group. ${ }^{10}$ The conjugated alkenenitriles 3 of $2 E$-configuration were exclusively obtained as the consequence of anti elimination of benzenethiol and the thermodynamic stability of products. Counterattack of the benzenethiolate ion on the intermediate $\mathbf{B}$ is shown for the reaction product 31 (Scheme 2). The diene-

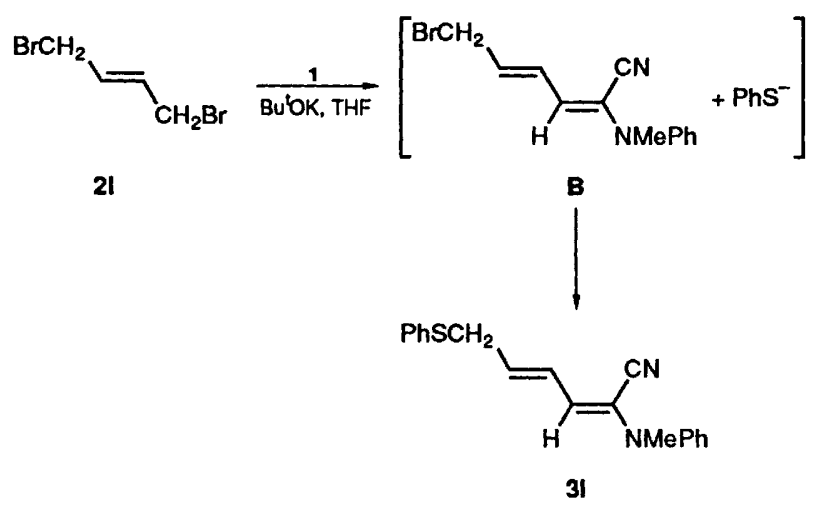

Scheme 2 nitrile $3 \mathrm{~m}$ is conceivably derived from desilylation of the intermediate $\mathbf{C}$ followed by addition of benzenethiol to the enyne intermediate $(\mathrm{Y}=\mathrm{H}$, Scheme 3$){ }^{11}$

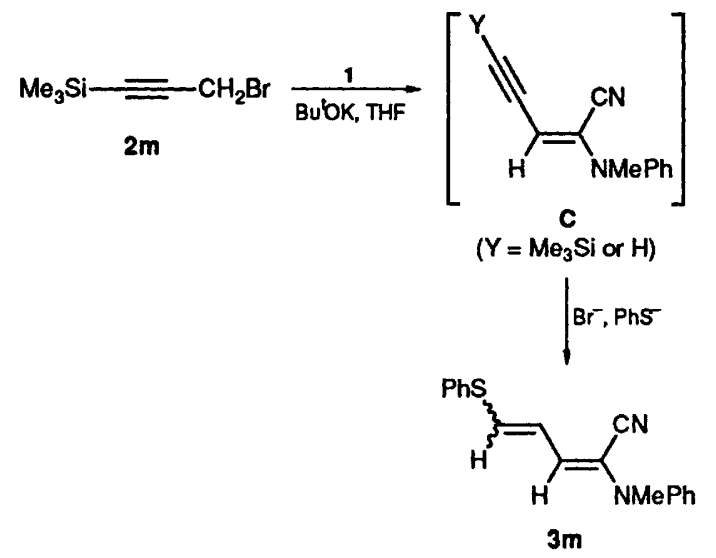

Scheme 3

In summary, utilisation of the title reagent to prepare conjugated $\alpha$-aminonitrile alkenes and dienes has several advantages: (1) The starting reagent 1 is stable and easily prepared on a large scale. (2) The reactions of 1 are simply brought about under mild conditions with the many readily available alkyl halides which may incorporate other functional groups. (3) The current method is stereoselective to afford $2 E$ alkenenitriles that cannot be realised in pure isomeric form by earlier methods. Besides a number of well-documented applications, ${ }^{2-4}$ the described $\alpha$-anilinoalkenenitriles $3 \mathbf{a}-\mathbf{m}$ may be further transformed by photochemical cyclisation into a variety of 2-cyanoindoles compounds of importance for alkaloid synthesis. $^{12}$

\section{Experimental}

Typical Procedure.-To a solution of ButOK $(113 \mathrm{mg}$, $1 \mathrm{mmol})$ in THF $(8 \mathrm{ml})$ was added a solution of $2-(N-$ methylanilino)-2-phenylthioacetonitrile $(254 \mathrm{mg}, 1 \mathrm{mmol})$ in THF $(2 \mathrm{ml})$ at room temperature. After $20 \mathrm{~min}$, the resulting 
pale yellow solution was treated with 1,3-dibromopropene (1.1 $\mathrm{mmol}, 0.11 \mathrm{ml}$ ). The brownish yellow turbid mixture was stirred at room temperature for $12 \mathrm{~h}$ and then quenched with saturated aqueous $\mathrm{NH}_{4} \mathrm{Cl}$. After removal of THF under reduced pressure the residue was extracted with EtOAc. The combined extracts were concentrated and passed through a column of silica gel to give the desired product 5-bromo-2-( $N$-methylanilino $)$ penta2,4-dienenitrile 3k (189 mg, 72\%).

\section{Acknowledgements}

We are grateful to the National Science Council for financial support of this work.

\section{References and Footnotes}

1 H. G. Viehe, Z. Janousek, R. Merenyi and L. Stella, Acc. Chem. Res., $1985,18,148$

2 H. Ahlbrecht and K. Pfaff, Synthesis, 1978, 897; 1985, 421; J. M. Fang and H. T. Chang, J. Chem. Soc., Perkin Trans. 1, 1988, 1945.

3 J. L. Boucher and L. Stella, Tetrahedron, 1985, 41, 875; J. M. Fang, C. C. Yang and Y. W. Wang, J. Org. Chem., 1989, 54, 477.

4 J. M. Fang, H. T. Chang and C. C. Lin, J. Chem. Soc., Chem. Commun., 1988, 1385.

5 B. Costisella and H. Gross, Tetrahedron, 1982, 38, 139; K. Takahashi,
K. Shibasaki, K. Ogura and H. Iida, J. Org. Chem., 1983, 48, 3566; J. M. Fang and C. C. Yang, J. Chem. Soc., Chem. Commun., 1985, 1356; C. C. Lin, M.S. Thesis, National Taiwan University, 1989.

6 D. Dopp and M. Pies, J. Chem. Soc., Chem. Commun., 1987, 1734.

7 J. Toye and L. Ghosez, J. Am. Chem. Soc., 1975, 97, 2276; B. Lesur, J. Toye, M. Chantrenne and L. Ghosez, Tetrahedron Lett., 1979, 2835.

8 Compound 1: $v_{\max }(\mathrm{KBr}) 2237 \mathrm{~cm}^{-1}(\mathrm{CN}) ; \mathrm{m} / \mathrm{z} 254[\mathrm{M}]^{+}, 145$ (base peak); $\delta_{\mathrm{H}}\left(\mathrm{CDCl}_{3}\right) 3.05\left(\mathrm{~s}, \mathrm{NCH}_{3}\right), 5.8(\mathrm{~s}, 1 \mathrm{H})$ and 6.8-7.6 $(\mathrm{m}, 10 \mathrm{H})$; $\delta_{\mathrm{C}}\left(\mathrm{CDCl}_{3}\right) 35.5\left(\mathrm{NCH}_{3}\right), 61.7(\mathrm{C}-2), 116.5(\mathrm{CN}), 121.5,129.5,129.6$, $129.9,135.7$ and 146.7. The analogous compound 2-dimethylamino2-methylthioacetonitrile has been reported as liquid (S. A. Okecha and F. Stansfield, J. Chem. Soc., Perkin Trans. 1, 1977, 1811).

9 The intermediate $A(R=M e)$ showed two singlets at $\delta_{H} 1.6$ and 3.15 attributable to the 2-Me and $N$-Me groups, while the one with $\mathbf{R}=$ $\mathrm{CH}_{2}=\mathrm{CHCH}_{2}$ displayed proton resonances at $\delta 2.6(\mathrm{~m}, 1 \mathrm{H}), 2.9(\mathrm{~m}$, $1 \mathrm{H}), 3.15(\mathrm{~s}, 3 \mathrm{H}), 5.0-5.2(\mathrm{~m}, 2 \mathrm{H}), 5.7-6.0(\mathrm{~m}, 1 \mathrm{H})$ and $7.0-7.4(\mathrm{~m}, 10$ H).

10 A. Padwa, W. Dent, H. Nimmesgern, M. K. Venkatramanan and G. S. K. Wong, Chem. Ber., 1986, 119, 813.

11 J. R. Hwu and B. A. Gilbert, Tetrahedron, 1989, 45, 1233.

12 H. T. Chang, M.S. Thesis, National Taiwan University, 1987.

Paper 0/04260I

Received 31st July 1990

Accepted 20th September 1990 